\title{
Tariff-Specific Preferences and Their Influence on Price Sensitivity
}

Agnieszka Wolk, Faculty of Business and Economics, Johann Wolfgang Goethe University, Frankfurt am Main, E-Mail: a.wolk@wiwi.uni-frankfurt.de Bernd Skiera, Faculty of Business and Economics, Johann Wolfgang Goethe University, Frankfurt am Main, E-Mail: skiera@skiera.de

\begin{abstract}
For many services, consumers can choose among a range of optional tariffs that differ in their access and usage prices. Recent studies indicate that tariff-specific preferences may lead consumers to choose a tariff that does not minimize their expected billing rate. This study analyzes how tariff-specific preferences influence the responsiveness of consumers' usage and tariff choice to changes in price. We show that consumer heterogeneity in tariff-specific preferences leads to heterogeneity in their sensitivity to price changes. Specifically, consumers with tariff-specific preferences are less sensitive to price increases of their preferred tariff than other consumers. Our results provide an additional reason why firms should offer multiple tariffs rather than a uniform nonlinear pricing plan to extract maximum consumer surplus.
\end{abstract}

Keywords: pricing, nonlinear pricing, tariff choice, tariff-specific preferences, price elasticity, flat rate, three-part tariffs, flat-rate bias, pay-per-use bias

Manuscript received November 30, 2008, accepted by Adamantios Diamantopoulos (Marketing), December 10, 2009 .

\section{Introduction}

For many services, such as telecommunication or online information, consumers can choose between a wide spectrum of optional pricing plans, including flat rates, pay-per-use tariffs, or two- and three-part tariffs. Because consumers' tariff choice affects their usage, the billing rate, and the company's profits, setting optimal prices is of great importance. Yet companies often experiment with different pricing schemes at great cost rather than make sound evidence-based decisions supported by market research (Essegaier, Gupta, and Zhang 2002; Schlereth, Stepanchuk, and Skiera 2010).

Standard economic theory assumes that a consumer chooses a tariff that minimizes the billing rate given his expected usage (Brown and Sibley 1986). However, empirical studies suggest that consumers base their tariff choices not only on the expected billing rate but also on tariff-specific preferences. For example, consumers may prefer a flat-rate tariff to usage-based pricing (Lambrecht and Skiera 2006;
Nunes 2000; Train, McFadden, and Ben-Akiva 1987). If tariff-specific preferences influence a consumer's tariff choice, such preferences should also affect his price sensitivity. However, most studies on tariff choice neglect the influence of tariff-specific preferences on price responsiveness assuming that consumers are homogeneous in their price sensitivity (Kling and van der Ploeg 1990; Lambrecht, Seim, and Skiera 2007; Lee 1999; Train, McFadden, and Ben-Akiva 1987). This may prompt suboptimal pricing strategy recommendations (Gensch 1985). The aim of this paper is to analyze how tariff-specific preferences influence the responsiveness of consumers' tariff choice and usage to price changes. In doing so, we aim to add to researchers' and managers' understanding of consumers' tariff choice and ultimately help to improve pricing decisions. We use attitudinal data to segment consumers by tariffspecific preferences and then exploit usage data to analyze how those preferences influence price elasticities - a common measure of price sensitivity 
(Kaul and Wittink 1995). A key feature of our approach is that we combine actual usage data with attitudinal data of the same consumers.

The paper is organized as follows: We first discuss related literature and introduce a conceptual model of the effect of tariff-specific preferences on tariff choice and usage. Next, we demonstrate how to empirically measure consumers' tariff choice and usage decisions when accounting for tariff-specific preferences. We then present our empirical study and results. We conclude with a discussion of the implications of our study.

\section{Literature review}

With a flat-rate tariff, consumers pay only an access price, whereas pay-per-use tariffs charge only a usage price. In a two-part tariff, consumers pay both an access price for obtaining access to the service and a usage price for the quantity used (Brown and Sibley 1986). In a three-part tariff, consumers obtain a usage allowance for paying the access price, for example, free minutes on a cell-phone plan, and then pay a usage price only when their usage exceeds the allowance (Lambrecht, Seim, and Skiera 2007).

It is often assumed that when choosing among menus of those tariffs, consumers prefer the tariff that minimizes their billing rate, given their expected usage (Brown and Sibley 1986; Iyengar, Jedidi, and Kohli 2008). Yet, recent studies indicate that many consumers choose a tariff that does not minimize their billing rate, but are subject to a flat-rate bias: Those consumers select a flat-rate or a tariff with a higher allowance even though they would pay less on a tariff that charges for actual usage. Alternatively, they may choose a tariff that charges for actual usage even though they would pay less on a flat rate (pay-per-use bias) (see among others Lambrecht and Skiera 2006; Miravete 2002; Nunes 2000; Train, McFadden, and Ben-Akiva 1987). These results suggest that, in addition to billing rate, choice of tariffs is also driven by consumers' preferences for tariff-specific characteristics, such as a high allowance.

Previous findings propose various effects to explain why consumers have a flat-rate bias. Since consumption likely varies monthly, the billing rate under a pay-pay-use tariff would also vary. Under a flat rate a consumer can avoid such variation in the monthly billing rate. Consequently, consumers who cannot predict their future consumption exactly, can choose a flat rate to insure against the risk of high costs in periods of higher-than-average usage; an effect dubbed as "insurance effect" (Miravete 2002; Train 1991; Winer 2005; Lambrecht and Skiera 2006). In addition, consumers may enjoy their usage more on a flat rate than on a pay-per-use tariff (also called "taxi meter effect"). The reason is that paying per use may lessen the joy from consumption, as the cost and thus the pain of paying are attributed to the consumption at the time of usage. In contrast, consumption is separated from payment under a flat rate as the costs are mentally prepaid, e.g., at the beginning of each month (Prelec and Loewenstein 1998).

The pay-per-use bias has not been as prevalent as the flat-rate bias. Lambrecht and Skiera (2006) show that the pay-per-use bias is both, less important and less regular than the flat-rate bias. Similarly its drivers were analyzed only to a limited extent. Train (1991) proposes risk aversion as a possible explanation for pay-per-use bias but provides no empirical support for this claim. The empirical result of Lambrecht and Skiera (2006) indicates that the pay-per-use bias is driven by the underestimation of usage.

In addition to factors that are tariff-specific, there also exist factors that may lead to both kinds of biases. Consumers may enjoy the convenience of not comparing various tariffs (called "convenience effect"). The convenience effect can lead to both flatrate bias and pay-per-use bias, which mainly depends on which tariff is traditionally offered on the market and which tariff has been used before by the consumer. Lambrecht and Skiera (2006) can, however, not confirm that the convenience effect leads to a bias. Other potential effects that may steer consumers toward a suboptimal tariff include the uncertainty about future demand when they make a tariff choice (Nunes 2000), including both usage overestimation and underestimation. Lambrecht and Skiera (2006) find empirical support for the notion that consumers suffer from making estimation errors in both directions. Not surprisingly, overestimation leads to a flat-rate bias, whereas underestimation is a major cause of pay-per-use bias. These effects, however, result from consumers' limited cognitive abilities and usage characteristics and as such do not reflect preferences for tariffs.

Marketing research provides ample evidence that attitudes guide behavior (e.g., Fazio and Zanna 1981). Consequently, we should also expect a con- 
sumer's tariff-specific preferences driven by the effects described above to affect his price sensitivity with respect to tariff choice and usage. There is, however, little research on the effect of tariff-specific preferences on consumers' price sensitivity. Below, we develop a framework that illustrates the effect of tariff-specific preferences on price sensitivity.

\section{Conceptual model}

\subsection{Influence of tariff-specific preferences on price sensitivity with respect to tariff choice}

When selecting a tariff, its price and the expected billing rate are important but are not the only choice criteria for consumers who care about the tariff's characteristics (e.g., the constant billing rate of a flat rate). Consumers with tariff-specific preferences may tend to choose their preferred tariff in spite of its higher price. Lichtenstein, Netemeyer, and Burton (1990) show that consumers often choose their favorite alternative even if it is more expensive. Consequently, we expect consumers with tariff preferences to be less sensitive to a price increase of their preferred tariff than consumers whose choice is exclusively guided by the expected billing rate. On the other hand, consumers who dislike characteristics of a given tariff, but still choose this tariff due to its low price, are likely to switch as soon as the price of this tariff increases and the only reason for choosing it disappears. As a result, we expect these con- sumers to be more responsive to price increases of the tariff they dislike.

In line with previous findings we define three segments of consumers: (1) Consumers that have a preference for flat rates, (2) consumers whose choice is not affected by tariff-specific characteristics and (3) consumers who dislike the characteristics of flat rates, which we will refer to as a flat-rate aversion. We expect consumers who prefer flat-rate tariffs to be less sensitive to increases in the access price of flat-rate tariffs, and more generally less sensitive to increases in the access and usage price of tariffs that share similar characteristics with flat rates (e.g., three-part tariffs with high usage allowances) than other consumers. Conversely, such consumers should be more sensitive to increases in usage price of pay-per-use tariffs, and more generally more sensitive to increases in the access and usage price of tariffs that have none or only a small usage allowance. We anticipate the opposite effect for consumers with a flat-rate aversion. We consequently expect price sensitivities to vary across segments as illustrated in Table 1 .

\subsection{Influence of tariff-specific preferences on price sensitivity with respect to usage} Companies aiming to set optimal prices need to understand how prices affect tariff choice as well as usage. Under optional tariffs, the usage price enters a demand function that is conditional on tariff choice (Brown and Sibley 1986; Train, McFadden,

Table 1: Expected price elasticities across tariffs with respect to tariff choice

\begin{tabular}{|c|c|c|c|c|c|c|c|}
\hline \multirow{2}{*}{ Tariff } & \multirow{2}{*}{ Tariff description } & \multicolumn{3}{|c|}{ Access price elasticity } & \multicolumn{3}{|c|}{ Usage price elasticity } \\
\hline & & $\begin{array}{l}\text { Flat rate } \\
\text { aversion } \\
\text { segment }\end{array}$ & $\begin{array}{c}\text { Tariff } \\
\text { indifference } \\
\text { segment }\end{array}$ & $\begin{array}{l}\text { Flat rate } \\
\text { preference } \\
\text { segment }\end{array}$ & $\begin{array}{l}\text { Flat rate } \\
\text { aversion } \\
\text { segment }\end{array}$ & $\begin{array}{c}\text { Tariff } \\
\text { indifference } \\
\text { segment }\end{array}$ & $\begin{array}{c}\text { Flat rate } \\
\text { preference } \\
\text { segment }\end{array}$ \\
\hline Tariff 1 & $\begin{array}{l}\text { Three-part tariff with } \\
\text { low access price and } \\
\text { allowance }\end{array}$ & Low & Middle & High & Low & Middle & High \\
\hline Tariff 2 & $\begin{array}{l}\text { Three-part tariff with } \\
\text { high access price and } \\
\text { allowance }\end{array}$ & Middle & Middle & Middle & High & Middle & Low \\
\hline Tariff 3 & Flat rate & High & Middle & Low & & & \\
\hline
\end{tabular}


and Ben-Akiva 1987). As a result, usage price influences demand directly as well as indirectly via its influence on tariff choice. The access price influences usage indirectly via its effect on tariff choice. We discuss the effect of access and usage price in turn.

\section{Access price}

The response to increasing the access price of a flat rate or a three-part tariff with a high allowance is consequently that consumers with a flat-rate aversion are more likely than other consumers to switch down to a tariff with a lower access price, a lower usage allowance, or a higher usage price. Because these switchers face a higher marginal price, their expected usage is likely to decrease. In sum, an increase of the access price of a tariff with a high access price and allowance decreases usage of consumers with a flat-rate aversion more than of consumers with a flat-rate preference simply because the latter are less likely to switch tariffs.

Further, if the company increases the access price of a tariff with a low usage allowance, consumers of that tariff are likely to switch up to a tariff with a higher allowance or lower usage price. Switchers thus face a lower marginal price, resulting in a higher expected usage. On average, the effect of an increase in access price of a tariff with a low usage allowance on usage is strongest for consumers with a flat-rate preference as they are more likely to switch up to a tariff with a higher access price, a higher usage allowance or a lower usage price. This effect will be lowest for consumers with a flat-rate aversion.

\section{Usage price}

Determining the effect of changes in usage prices on usage is less obvious. An increase in the usage price reduces the usage of those consumers who stay on the same tariff. Yet, an increase in the usage price might also induce consumers to switch up to tariffs with a higher access price, a higher usage allowance or a lower usage price, which would consequently increase their usage (Train, McFadden, and BenAkiva 1987). Therefore, two opposite effects are likely to take place as a result of usage price increase. We expect a high negative effect of a price increase on usage for consumers that have a flatrate aversion because they are less likely to switch up to tariffs with higher allowances. On the other hand, consumers that have a flat-rate preference are more likely to switch up to a tariff with a higher access price or a higher allowance which will increase their usage. Therefore, we expect a positive effect for them. Table 2 summarizes the effects. We next aim to empirically validate differences in price sensitivities across segments.

\section{Methodology}

Previous literature finds that two attitudinal effects influence tariff-specific preferences: the taxi meter and the insurance effect (Lambrecht and Skiera

Table 2: Expected price elasticities across tariffs with respect to usage

\begin{tabular}{|c|c|c|c|c|c|c|c|}
\hline \multirow{2}{*}{ Tariff } & \multirow{2}{*}{ Tariff description } & \multicolumn{3}{|c|}{ Access price elasticity } & \multicolumn{3}{|c|}{ Usage price elasticity } \\
\hline & & $\begin{array}{l}\text { Flat-rate } \\
\text { aversion } \\
\text { segment }\end{array}$ & $\begin{array}{c}\text { Tariff- } \\
\text { indifference } \\
\text { segment }\end{array}$ & $\begin{array}{l}\text { Flat-rate } \\
\text { preference } \\
\text { segment }\end{array}$ & $\begin{array}{l}\text { Flat-rate } \\
\text { aversion } \\
\text { segment }\end{array}$ & $\begin{array}{c}\text { Tariff- } \\
\text { indifference } \\
\text { segment }\end{array}$ & $\begin{array}{c}\text { Flat-rate } \\
\text { preference } \\
\text { segment }\end{array}$ \\
\hline Tariff 1 & $\begin{array}{l}\text { Three-part tariff with } \\
\text { low access price and } \\
\text { allowance }\end{array}$ & $\begin{array}{c}\text { Positive } \\
\text { low }\end{array}$ & $\begin{array}{l}\text { Positive } \\
\text { middle }\end{array}$ & $\begin{array}{l}\text { Positive } \\
\text { high }\end{array}$ & $\begin{array}{c}\text { Negative } \\
\text { high }\end{array}$ & $\begin{array}{l}\text { Negative } \\
\text { middle }\end{array}$ & $\begin{array}{c}\text { Positive } \\
\text { high }\end{array}$ \\
\hline Tariff 2 & $\begin{array}{l}\text { Three-part tariff with } \\
\text { high access price and } \\
\text { allowance }\end{array}$ & $\begin{array}{l}\text { Negative } \\
\text { middle }\end{array}$ & $\begin{array}{c}\text { Negative } \\
\text { low }\end{array}$ & $\begin{array}{l}\text { Positive } \\
\text { middle }\end{array}$ & $\begin{array}{l}\text { Negative } \\
\text { middle }\end{array}$ & $\begin{array}{c}\text { Negative } \\
\text { low }\end{array}$ & $\begin{array}{l}\text { Positive } \\
\text { middle }\end{array}$ \\
\hline Tariff 3 & Flat rate & $\begin{array}{c}\text { Negative } \\
\text { high }\end{array}$ & $\begin{array}{l}\text { Negative } \\
\text { middle }\end{array}$ & $\begin{array}{c}\text { Negative } \\
\text { low }\end{array}$ & & & \\
\hline
\end{tabular}


2006). We use the multi-item scales as in Lambrecht and Skiera (2006) to identify consumers with (1) a flat-rate preference, (2) a flat-rate aversion, and (3) tariff-indifference. Consumers that score 4 or higher on the 5-point Likert scale for either the taxi meter effect or the insurance effect, and as such agree or strongly agree to have a preference for a flat rate, are assigned to the flat-rate preference segment. Consumers who score 2 or lower on both scales are classified as the flat-rate aversion segment. The remaining consumers constitute the segment that is indifferent between tariff-specific characteristics. Thus, we group consumers based on their attitudes and then estimate a tariff choice model for each group. Such an approach is particularly suitable for our study because the goal is to explore and understand differences between known groups.

We use transactional data from an Internet provider to model consumers' usage and tariff choice decisions. In modeling tariff choice, researchers need to account for the interdependency between tariff choice and actual usage. A consumer with high usage typically chooses a flat rate while low usage of a consumer is related to a measured tariff. On the other hand, once a household chooses a specific tariff, its usage is likely to be affected by this choice. Theoretical and empirical research show that consumers likely increase their usage having chosen a flat-rate tariff whereas a pay-per-use tariff makes them decrease their usage (Brown and Sibley 1986; Altmann and Chu 2001; Narayanan, Chintagunta, and Miravete 2007; Iyengar, Ansari, and Gupta 2007; Lambrecht, Seim, and Skiera 2007). In order to account for those interdependencies between tariff choice and usage level we follow Train, McFadden, and Ben-Akiva (1987) and Lee (1999) and estimate a nested logit model. We assume that consumer $i$ chooses Internet usage amount (i.e., usage portfolio $p$ ) and then given the chosen usage portfolio $p$ chooses tariff $t$. Such a direction reflects the fact that consumers use their expectations about the usage amount to make a tariff decision. This sequence of decisions has been tested in Train, BenAkiva, and Atherton (1989) and applied in Train, McFadden, and Ben-Akiva (1987). Thus, the interdependency is captured in such a way that the tariff choice is conditional on the usage portfolio choice. Additionally, when making a usage portfolio choice the utility of the tariffs available for this portfolio are taken into account in an inclusive value. This results in the following model specification:

$$
\text { (1) } P_{p t i}=\frac{\exp \left(U_{p t i}\right)\left(\sum_{T} \exp \left(U_{p T i}\right)^{\lambda-1}\right)}{\sum_{P} \sum_{T} \exp \left(U_{P T i}\right)^{\lambda}}
$$

where $P_{p t i}$ is a probability that consumer $i$ chooses usage portfolio $p$ from a set of possible usage portfolios $P$ and tariff $t$ from a set of possible tariffs $T, U_{p t i}$ is consumer $i$ 's utility of choosing usage portfolio $p$ and tariff $t$. We can rewrite the probability $P_{p t i}$ as a product of the marginal probability that consumer $i$ chooses the usage portfolio $p, P_{p i}$, and the conditional probability that he chooses tariff $t$ given usage portfolio $p, P_{t / p i}$, as follows:

(2) $P_{p t i}=P_{p i} P_{t / p i}$

We further define in (3) the marginal probability $P_{p i}$ that consumer $i$ chooses usage portfolio $p$. Since the consumer can choose any Internet usage amount, the number of possible usage portfolios from which the consumer can choose quickly becomes immense. Including all those portfolios in the probability function is, however, infeasible (Train, McFadden, and Ben-Akiva 1987; Train, Ben-Akiva, and Atherton 1989). Therefore, for each consumer $i$ we create a sample of usage portfolios by drawing from the set of all portfolios that are pre-specified by the observed consumer usage pattern. As a result, for each consumer we obtain a set of sample portfolios, $W_{i}$, which includes the consumer's chosen portfolio and a subset of nine other portfolios which are used in the probability specification (3). In order to correct for the bias introduced by the sampling of alternatives we include a correction term, $\ln \left(P\left(W_{i} / p\right)\right)$. This approach is similar to the one used in Train, McFadden, and Ben-Akiva (1987) and results in the following portfolio choice probability specification:

(3)

$$
P_{p i / W i}=\frac{\exp \left(\phi \log N_{p i} V_{p i}-\alpha N_{p i}+\lambda I_{p i}+\ln P\left(W_{i} / p\right)\right)}{\sum_{W} \exp \left(\phi \log N_{p i} V_{p i}-\alpha N_{p i}+\lambda I_{p i}+\ln P\left(W_{i} / p\right)\right)}
$$

Each usage portfolio is defined by the number of logins to the Internet per month $(N)$ and the average data volume transferred per login $(V)$. Such a definition allows for capturing the distinctive characteristics of the Internet usage pattern. The total data 
volume transferred per month results from multiplying the number of logins and the average data volume per login. In the portfolio utility specification, we recognize that the Internet usage provides both benefits and opportunity costs. The first term, $N_{p i} V_{p i}$, captures the total volume transferred in a month and represents the benefits of Internet usage that increase with the volume. Since the benefits increase with an increasing volume we expect to obtain a positive value for coefficient $\phi$. According to the expected decreasing marginal utility of the benefits, we use logarithmic values, i.e. $\ln \left(N_{p i} V_{p i}\right)$. Since every login to the Internet is time consuming, $N_{p i}$ represents the opportunity costs of time for every login to the Internet. Since the opportunity costs decrease the utility, $N_{p i}$ enters the utility specification with a negative sign (as such we include a negative sign before coefficient $\alpha$ ). Lastly, $I_{p i}$ is the inclusive value which represents the utility for consumer $i$ of tariff options in the usage portfolio choice $p$ :

(4) $I_{p i}=\ln \left(\sum_{T} \exp \left(\beta_{1 T}+\beta_{2} B_{p T i}\right)\right)$

where $B_{p t i}$ indicates the consumers i's billing rate for a given usage portfolio $p$ under a given tariff $t$. As such, the choice of usage portfolio depends on the expected billing rate under all available tariffs. Coefficient $\lambda$ indicates the substitutability across alternatives. Values between 0 and 1 indicate higher switching within than among nests, which means that the consumer more likely changes tariffs than usage portfolios. If the coefficient is higher than 1, the consumer more likely changes his usage portfolio than his tariff.

The choice of the tariff depends on the tariff-specific constant and the consumer's billing rate for this tariff, conditional on the choice of usage portfolio $B_{p t i}$. The billing rate is calculated by multiplying the usage amount by the marginal price in case of measured options. In case of a flat rate, the billing rate constitutes a fixed fee. Consequently, we define consumer $i$ s conditional probability of choosing tariff $t$ given usage portfolio $p$ as:

(5) $P_{t / p i}=\frac{\exp \left(\beta_{1 t}+\beta_{2} B_{p t i}\right)}{\sum_{T} \exp \left(\beta_{1 t}+\beta_{2} B_{p T i}\right)}$

Assuming rationally behaving consumers, we expect that the lower the billing rate under a given tariff, the higher the probability of choosing this tariff.
Therefore, we expect a negative relationship between the billing rate and the tariff choice expressed in the negative coefficient $\beta_{2}$.

\section{Data}

We use attitudinal and transactional data of consumers of a German Internet service provider. The provider offered three different tariffs in 2003: (1) Tariff 1, a three-part tariff with a low access price and a low monthly allowance; (2) Tariff 2, a threepart tariff with a higher access price and a higher allowance than Tariff 1 but the same usage price; and (3) Tariff 3, a flat rate with unlimited usage. The data includes the tariff choice and the monthly usage measured in megabytes for 11,745 customers over a time period of up to five months, a total of 49,107 monthly usage observations. The prices for each tariff were constant in the observation period. Information about latent attitudes comes from an online survey conducted among a representative sample of customers of the Internet service provider. The survey consists of items that measure the taxi meter and insurance effects on a 5-point Likert scale (1 - strongly disagree, 5 - strongly agree) (Lambrecht and Skiera 2006). From the sample of 12,000 customers, we obtain 1,078 complete responses. For 941 consumers we match the transactional data to the survey data which constitutes our final sample with 3,910 monthly observations (for 35 consumers we observe 2 months, for $186-3$ months, for $318-4$ months, and for $402-5$ months).

Average monthly Internet usage is equal to 2,033MB with 1,999MB in January, 2,132 in February, 1,878 in March, 1,986 in April, 1,974 in May and 2,585 in June (ANOVA shows no significant differences between months, $\mathrm{p}=0.579$ and no significant linear trend in usage $\mathrm{p}=0.333$ ). On the individual consumer level, we observe 677 consumers with no significant trend in usage; in the case of 85 consumers, we observe a negative trend in usage; and in 144 we observe a positive trend in usage (consumers with two observation periods were excluded from the analysis).

Out of 941 analyzed consumers, 664 consumers always chose the bill-minimizing tariff whereas 277 consumers at least once in the observation period chose a suboptimal tariff ( 88 consumers who chose a suboptimal tariff once, 57 - twice, 58 - three times, 41 - four times and $33-5$ times). In 3,205 
Table 3: Results from model estimation

\begin{tabular}{|c|c|c|c|c|c|}
\hline & \multirow[b]{2}{*}{ Model 1} & \multirow[b]{2}{*}{ Model 2} & \multicolumn{3}{|c|}{ Model 3} \\
\hline & & & $\begin{array}{c}\text { Flat-rate aversion } \\
\text { segment }\end{array}$ & $\begin{array}{c}\text { Tariff-indifference } \\
\text { segment }\end{array}$ & $\begin{array}{l}\text { Flat-rate pref- } \\
\text { erence segment }\end{array}$ \\
\hline \multicolumn{6}{|l|}{ Tariff choice } \\
\hline Intercept tariff $1\left(\beta_{11}\right)$ & $1.70^{* * * *}$ & $2.05^{* * *}$ & $2.93^{* * * *}$ & $4.21^{* * * *}$ & $1.58^{* * *}$ \\
\hline Intercept tariff $2\left(\beta_{12}\right)$ & $0.64^{* * *}$ & $1.86^{* * * *}$ & 0.70 & $2.90^{* * * *}$ & $1.61^{* * * *}$ \\
\hline Billing rate $\left(\beta_{2}\right)$ & $-0.09^{* * * *}$ & $-0.06^{* * *}$ & $-0.16^{* * *}$ & $-0.10^{* * * *}$ & $-0.05^{* * * *}$ \\
\hline \multicolumn{6}{|l|}{ Portfolio choice } \\
\hline Benefit $(\phi)$ & $0.26^{* * * *}$ & $0.33^{* * * *}$ & $0.45^{* * * *}$ & $0.39^{* * * *}$ & $0.34^{* * * *}$ \\
\hline $\operatorname{Cost}(\alpha)$ & $0.0002^{* * *}$ & $0.002^{* * * *}$ & $0.006^{* * *}$ & $0.004^{* * * *}$ & $0.001^{* * *}$ \\
\hline Inclusive value $(\lambda)$ & $1.10^{* * * *}$ & $1.19^{* * * *}$ & $1.03^{* * * *}$ & $0.98^{* * * *}$ & $1.42^{* * * *}$ \\
\hline Log likelihood & $-138,796.40$ & $-11,423.97$ & & & $-10,505.07$ \\
\hline Number of Parameters & 6 & 6 & & & 18 \\
\hline Number of Observations & 49,023 & 3,910 & & & 3,910 \\
\hline \multirow{2}{*}{ Segment size } & & & 287 & 1,698 & 1,925 \\
\hline & & & $7 \cdot 34 \%$ & $43.43 \%$ & $49.23 \%$ \\
\hline
\end{tabular}

${ }^{* * * *}$ Significant at $0.01,{ }^{* *}$ Significant at $0.05,{ }^{*}$ Significant at 0.10.

cases (82\% all observations) the cost-minimizing tariff was chosen, in 488 cases $(12.5 \%$ all observations) the tariff with higher allowance than optimal was chosen (flat-rate bias) and in 217 cases (5.5\% all observations) the tariff with lower allowance than optimal was chosen (pay-per-use bias).

\section{Results}

\subsection{Measurement of constructs}

The results of the confirmatory factor analysis indicate good overall model fit: $\chi^{2} / \mathrm{df} 3.19$, root mean square error of approximation 0.05 , goodness-of-fit index 0.99, adjusted goodness-of-fit index 0.98 , normed-fit index 0.99, Tucker-Lewis index 0.98, and confirmatory fit index 0.99. The individual factors have coefficient alphas of 0.80 and 0.58 , construct reliabilities of 0.81 and 0.65 , and variance extracted estimates of 0.513 and 0.506 for the taxi meter and insurance effects, respectively. All measures for scale reliability exceed critical values. Except for two, all item reliabilities exceed 0.4, and all t-values for factor loadings exceed 10.0 $(p<0.01)$.
All corrected item-to-total correlations are greater than 0.40 .

\subsection{Segmentation of customers}

As laid out in Section 3, we divide our sample into three groups based on survey results: (1) a flat-rate preference segment, (2) a flat-rate aversion segment, and (3) a tariff-indifference segment. 49\% of consumers have a flat-rate preference, $7 \%$ a flat-rate aversion, and $43 \%$ belong to the tariff-indifferent segment. These results are similar to the findings of Prelec and Loewenstein (1998).

\subsection{Results of tariff choice model}

Table 3 presents the results of different tariff choice models. Model 1 is based on the full sample. Models 2 and 3 refer to the subset of consumers who participated in the survey. Model 3 also accounts for tariff-specific preferences. The similar pattern across models 1 and 2 confirms that our subset of consumers is representative. A comparison of models 2 and 3 shows that accounting for tariff-specific preferences improves model fit. The likelihood ratio 
test shows a significant increase in log likelihood when we segment consumers according to their tariff-specific preferences and rejects the hypothesis of equal response parameters between segments $\left(\mathrm{LR}=43,858.07>\chi_{12 ; 0.95}^{2}=21.03\right)$. Model 3 also has greater explanatory power than model $2\left(\mathrm{R}^{2}=\right.$ 0.21 compared with 0.14).

We focus on the results of model 3 . As expected, the billing rate decreases tariff choice probabilities, an effect that is most pronounced for the flat-rate aversion segment $\left(\beta_{2}=-0.16\right)$. The results with respect to the choice of a usage portfolio are in line with our expectations: Benefits from using the Internet increase, whereas opportunity costs decrease the probability of choosing a given usage portfolio. The coefficients of the inclusive value for the flat-rate preference and flat-rate aversion segments are greater than 1 ( $\lambda=1.42$ and $\lambda=1.03$, respectively). This result indicates that consumers who like or dislike tariff-specific characteristics respond to changes in the billing rate more readily by adjusting their usage rather than by switching their tariff. By contrast, consumers who are indifferent between tariffs switch tariffs more easily than usage levels, as indicated by a coefficient of the inclusive value below 1 ( $\lambda=0.98$ for tariff-indifference segment). These patterns are consistent with our expectations: Consumers who prefer a certain type of tariff are more likely to keep that tariff and adjust their usage than to switch to a different tariff in response to price changes. In contrast, consumers with no tariff- specific preferences find it easier to switch in case of a price change.

To check the stability of our results, we estimate the described models by using another segmentation rule. Consumers that score 4 and higher on the taxi meter effect and the insurance effect measures are assigned to the flat-rate preference segment, those who score 2 or lower on both measures are assigned to the flat-rate aversion segment, and the remainders are assigned to the indifferent segment. According to this rule, the size of the flat-rate preference segment decreases from $49 \%$ to $17 \%$, and the size of a tariff-indifference segment increases from $43 \%$ to $76 \%$, while the flat-rate aversion segment does not change. The results provide a consistent pattern for both segmentation rules used (see Appendix).

\subsection{Price elasticities of tariff choice}

Based on the parameter estimates we compute the price elasticities of tariff choice per segment (percentage change in choice divided by the percentage increase in access or usage price). All elasticities have the expected negative sign, but clearly differ by segment (see Table 4). Consumers with tariffspecific preferences tend to be less sensitive to price increases of their preferred tariff than other segments. Specifically, consumers who prefer flat-rate tariffs are less sensitive to an increase in the access price of the flat rate than consumers with a flat-rate aversion (-0.85 versus -1.62). These results imply that consumers with a flat-rate preference are less

Table 4: Price elasticities of tariff choice

\begin{tabular}{|c|c|c|c|c|c|c|c|}
\hline \multirow[b]{2}{*}{ Tariff } & \multirow[b]{2}{*}{ Tariff description } & \multicolumn{3}{|c|}{ Access price elasticity } & \multicolumn{3}{|c|}{ Usage price elasticity } \\
\hline & & $\begin{array}{l}\text { Flat-rate } \\
\text { aversion } \\
\text { segment }\end{array}$ & $\begin{array}{c}\text { Tariff - } \\
\text { indifference } \\
\text { segment }\end{array}$ & $\begin{array}{l}\text { Flat-rate } \\
\text { preference } \\
\text { segment }\end{array}$ & $\begin{array}{l}\text { Flat-rate } \\
\text { aversion } \\
\text { segment }\end{array}$ & $\begin{array}{c}\text { Tariff- } \\
\text { indifference } \\
\text { segment }\end{array}$ & $\begin{array}{c}\text { Flat-rate } \\
\text { preference } \\
\text { segment }\end{array}$ \\
\hline Tariff 1 & $\begin{array}{l}\text { Three-part tariff } \\
\text { with low access price } \\
\text { and allowance }\end{array}$ & -0.04 & -0.09 & -0.16 & -0.03 & -0.08 & -0.10 \\
\hline Tariff 2 & $\begin{array}{l}\text { Three-part tariff } \\
\text { with high access } \\
\text { price and allowance }\end{array}$ & -1.61 & -1.00 & -0.40 & -0.06 & -0.05 & -0.03 \\
\hline Tariff 3 & Flat rate & -1.62 & -1.23 & -0.85 & & & \\
\hline
\end{tabular}




\begin{tabular}{|c|c|c|c|c|c|c|c|}
\hline \multirow{2}{*}{ Tariff } & \multirow{2}{*}{ Tariff description } & \multicolumn{3}{|c|}{ Access price elasticity } & \multicolumn{3}{|c|}{ Usage price elasticity } \\
\hline & & $\begin{array}{l}\text { Flat-rate } \\
\text { aversion } \\
\text { segment }\end{array}$ & $\begin{array}{c}\text { Tariff- } \\
\text { indifference } \\
\text { segment }\end{array}$ & $\begin{array}{l}\text { Flat-rate } \\
\text { preference } \\
\text { segment }\end{array}$ & $\begin{array}{l}\text { Flat-rate } \\
\text { aversion } \\
\text { segment }\end{array}$ & $\begin{array}{c}\text { Tariff- } \\
\text { indifference } \\
\text { segment }\end{array}$ & $\begin{array}{c}\text { Flat-rate } \\
\text { preference } \\
\text { segment }\end{array}$ \\
\hline Tariff 1 & $\begin{array}{l}\text { Three-part tariff } \\
\text { with low access price } \\
\text { and allowance }\end{array}$ & 0.07 & 0.08 & 0.09 & -0.25 & -0.20 & -0.06 \\
\hline Tariff 2 & $\begin{array}{l}\text { Three-part tariff } \\
\text { with high access } \\
\text { price and allowance }\end{array}$ & -0.12 & -0.14 & 0.08 & -0.08 & -0.04 & -0.01 \\
\hline Tariff 3 & Flat rate & -0.53 & -0.04 & -0.05 & & & \\
\hline
\end{tabular}

likely to switch down to a three-part tariff in case of an increase of the access price of a flat-rate than consumers with a flat-rate aversion. Further, consumers with a flat-rate aversion are least sensitive to an increase of the access and usage price of tariff 1 which is the tariff with the lowest allowance (-0.04 and -0.03 for access and usage price in case of flatrate aversion segment compared to -0.16 and -0.10 for access and usage price in case of flat-rate preference segment). These results suggest that flat-rate averse consumers who face an increase of the access and usage price of a three-part tariff with a low allowance are more likely to stay with this tariff than consumers with a flat-rate preference.

\subsection{Price elasticities of usage}

Table 5 shows the price elasticities of usage. The differences between segments indicate that tariffspecific preferences also influence how consumers' usage responds to price increases. An increase of the access price of tariff 1 has the greatest positive effect on usage in the flat-rate preference segment as these consumers are most likely to switch up to a tariff with a greater allowance (elasticity in the flat-rate preference segment is 0.09, compared to 0.07 in the flat-rate aversion segment). Increasing the access price of tariff 2 decreases usage among consumers with a flat-rate aversion (price elasticity -0.12) that are likely to switch down to tariff 1 , but increases usage among customers with a preference for a flatrate tariff (price elasticity 0.08 ) that have a high probability to switch up to a flat rate. Finally, the increase in the access price of a flat-rate tariff decreases usage in all segments, with the highest effect in the flat-rate aversion segment (-0.53 in the flatrate aversion segment compared to -0.05 in the flatrate preference segment).

We turn to the usage price sensitivity. An increase in the usage price has a stronger negative effect in the flat-rate aversion segment (-0.25 and -0.08) than in the flat-rate preference segment (-0.06 and o.01). This stronger negative effect in the flat-rate aversion segment occurs because this segment is less likely to switch up to tariffs with a higher allowance or usage price. These consumers stay on their current tariff and decrease their usage. While the negative values in the flat-rate preference segment are inconsistent with our proposition, the results still support our expectation that in the flat-rate preference segment the high extent of switching to a flat-rate compensates for changes in the usage of customers who remain in tariffs 1 and 2.

\section{Conclusions and implications}

Despite recent studies that indicate heterogeneity in consumers' tariff-specific preferences, most research on tariff choice assumes that consumers are homogenous in their tariff choice and price sensitivity. We address this limitation and analyze the extent of tariff-specific preferences and their influence on consumers' price elasticity of tariff choice and usage. 
The results show that accounting for tariff-specific preferences when modeling tariff choice significantly improves the model fit. Further, we show that tariff-specific preferences influence consumers' price sensitivity with respect to both tariff choice and usage. Consumer's tariff choice is less sensitive to price increases of their preferred tariff. More specifically, consumers with a flat-rate preference are relatively insensitive to increases in the access and the usage price of tariffs that have a high or unlimited usage allowance. By contrast, consumers with a flat-rate aversion are relatively insensitive to increases in the access and usage prices of tariffs with a low usage allowance. Likewise, we find heterogeneity in how consumers' usage responds to price changes: Increasing the usage price has a strong negative effect on usage in the flat-rate aversion segment and only a moderate negative effect in the flat-rate preference segment. The latter segment is more likely to switch up to a tariff with a higher allowance. On the other hand, increasing the access price of a tariff with a low allowance may increase usage. This effect is greatest in the flat-rate prefer- ence segment. Those consumers are more likely to switch up to tariffs with greater allowances where they are more likely to face a marginal price of zero. Our results show that a company can use prices to steer consumers' tariff choice and thus their usage. Likewise, a policy maker may consider price regulation that fosters socially approved behavior.

Finally, we find that when facing a price increase, consumers with tariff-specific preferences are more likely to adjust their usage, whereas consumers with no tariff-specific preferences more likely adjust their tariffs. These results complement existing studies. Whereas Iyengar (2005) argues that consumers actively try to control their usage costs by either switching tariffs or adjusting their consumption patterns, other studies report tariff stickiness (Lee 1999; Train, McFadden, and Ben-Akiva 1987). Our results demonstrate that this heterogeneity in observed switching behavior may be caused by tariffspecific preferences.

\section{Acknowledgments}

The authors would like to thank Anja Lambrecht for providing many helpful comments and suggestions.

\section{Appendix: Results from stability check of results of Table 3}

\begin{tabular}{|c|c|c|c|}
\hline & \multicolumn{3}{|c|}{ Model 3} \\
\hline & $\begin{array}{c}\text { Flat-rate aversion } \\
\text { segment }\end{array}$ & $\begin{array}{c}\text { Tariff-indifference } \\
\text { segment }\end{array}$ & $\begin{array}{c}\text { Flat-rate preference } \\
\text { segment }\end{array}$ \\
\hline \multicolumn{4}{|l|}{ Tariff choice } \\
\hline Intercept tariff $1\left(\beta_{11}\right)$ & $2.93^{* * *}$ & $2.03^{* * * *}$ & $1.92^{* * *}$ \\
\hline Intercept tariff $2\left(\beta_{12}\right)$ & 0.70 & $1.82^{* * *}$ & $1.34^{* * *}$ \\
\hline Billing rate $\left(\beta_{2}\right)$ & $-0.16^{* * *}$ & $-0.07^{* * *}$ & $-0.06^{* * *}$ \\
\hline \multicolumn{4}{|l|}{ Portfolio choice } \\
\hline Benefit $(\phi)$ & $0.45^{* * *}$ & $0.40^{* * *}$ & $0.27^{* * * *}$ \\
\hline $\operatorname{Cost}(\alpha)$ & $0.006^{* * *}$ & $0.003^{* * *}$ & $0.002^{* * *}$ \\
\hline Inclusive value $(\lambda)$ & $1.03^{* * * *}$ & $1.15^{* * *}$ & $1.01^{* * * *}$ \\
\hline Log likelihood & & & $-10,426.48$ \\
\hline Number of Parameters & & & 18 \\
\hline Number of Observations & & & 3,910 \\
\hline \multirow{2}{*}{ Segment size } & 287 & 2,973 & 650 \\
\hline & $7 \cdot 34 \%$ & $76.04 \%$ & $16.62 \%$ \\
\hline
\end{tabular}

${ }^{* * * *}$ Significant at $0.01,{ }^{* *}$ Significant at $0.05,{ }^{*}$ Significant at 0.10 . 


\section{References}

Altman, Jörn and Karyen Chu (2001): How to Charge for the Network Services - Flat Rate or Usage-Based?, Computer Network, 36 (5-6): 519-531.

Brown, Stephen J. and David S. Sibley (1986): The Theory of Public Utility Pricing, Cambridge University Press: Cambridge, UK.

Essegaier, Skander, Sunil Gupta, and Z. John Zhang (2002): Pricing Access Services, Marketing Science, 21 (2): 139-159.

Fazio, Russell H. and Mark P. Zanna (1981): Direct Experience and Attitude-Behavior Consistency, in: Leonard Berkowitz (ed.): Advances in Experimental Social Psychology 14, Academic Press: New York, 161-202.

Gensch, Dennis H. (1985): Empirically Testing a Disaggregate Choice Model for Segments, Journal of Marketing Research, 22 (4): 462-467.

Iyengar, Raghuram (2005): A Structural Demand Analysis for Wireless Services under Nonlinear Pricing Schemes, Working Paper, Columbia University.

Iyengar, Raghuram, Asim Ansari, and Sunil Gupta (2007): A Model of Consumer Learning for Service Quality and Usage, Journal of Marketing Research, 44 (4): 529-544.

Iyengar, Raghuram, Kamel Jedidi, and Rajeev Kohli (2008): A Conjoint Approach to Multipart Pricing, Journal of Marketing Research, 45 (2): 195-210.

Kaul, Anil and Dick R. Wittink (1995): Empirical Generalizations about the Impact of Advertising on Price Sensitivity and Price, Marketing Science, 14 (3): G151-G160.

Kling, John P. and Stephen S. van der Ploeg (1990): Estimating Local Elasticities with a Model of Stochastic Class of Service and Usage Choice, in: Alain de Fontenay, Mary H. Shugard, and David S. Sibley (eds.): Telecommunications Demand Modelling. An Integrated View, North Holland: Amsterdam, 119-136.

Lambrecht, Anja and Bernd Skiera (2006): Paying Too Much and Being Happy About It: Existences, Causes, and Consequences of Tariff-Choice Biases, Journal of Marketing Research, 43 (2): 212223.

Lambrecht, Anja, Katja Seim, and Bernd Skiera (2007): Does Uncertainty Matter? Consumer Behavior under Three-Part Tariffs, Marketing Science, 26 (5): 698-710.

Lee, Bosang (1999): Calling Patterns and Usage of Residential Toll Service under Self Selecting Tariffs, Journal of Regulatory Economics, 16 (1): 45-82.
Lichtenstein, Donald R., Richard G. Netemeyer, and Scot Burton (1990): Distinguishing Coupon Proneness from Value Consciousness: An Acquisition-Transaction Utility Theory Perspective, Journal of Marketing, 54 (3): 54-67.

Miravete, Eugenio J. (2002): Choosing the Wrong Calling Plan? Ignorance and Learning, American Economic Review, 93 (1): 297-310.

Narayanan, Sridhar, Pradeep K. Chintagunta, and Eugenio J. Miravete (2007): The Role of Self Selection, Usage Uncertainty and Learning in the Demand for Local Telephone Service, Quantitative Marketing and Economics, 5 (1): 1-34.

Nunes, Joseph C. (2000): A Cognitive Model of People's Usage Estimations, Journal of Marketing Research, 37 (4): 397-409.

Prelec, Drazen and George Loewenstein (1998): The Red and the Black: Mental Accounting of Savings and Debt, Marketing Science, 17 (1): 4-28.

Schlereth, Christian, Tanja Stepanchuk, and Bernd Skiera (2010): Optimization and Analysis of the Profitability of Tariff Structures with Two-Part Tariffs, European Journal of Operational Research, 206 (3), 691-701.

Train, Kenneth E. (1991): Optimal Regulation: The Economic Theory of Natural Monopoly, MIT Press: Cambridge, MA.

Train, Kenneth E., Daniel L. McFadden, and Moshe Ben-Akiva (1987): The Demand for Local Telephone Service: A Fully Discrete Model of Residential Calling Patterns and Service Choices, Rand Journal of Economics, 18 (1): 109-123.

Train, Kenneth E., Moshe Ben-Akiva, and Terry Atherton (1989): Consumption Patterns and Self-selecting Tariffs, Review of Economics and Statistics, 71 (1): 62-73.

Winer, Russel S. (2005): Pricing. Marketing Science Institute: Cambridge, MA.

\section{Biographies}

Agnieszka Wolk holds a Ph.D. in Marketing from Johann Wolfgang Goethe University of Frankfurt, Germany. Her research focuses on various forms of price discrimination including quantity-based and channel-based price discrimination.

Bernd Skiera is a Professor of Electronic Commerce at the Johann Wolfgang Goethe University of Frankfurt, Germany, and a member of the board of the E-Finance Lab. His research focuses on pricing, electronic commerce, online marketing, in particular search engine marketing, prediction markets, and customer management. 